\title{
La responsabilidad precontractual desde una perspectiva del derecho de contratos**
}

DOI: dx.doi.org/10.15425/2017.352

\section{Resumen}

La responsabilidad precontractual ha ganado notoriedad en el derecho contemporáneo. En términos generales parece existir acuerdo sobre su procedencia, sus elementos estructurantes y la extensión del daño. Su naturaleza, por el contrario, ha sido menos pacífica. El desencuentro viene dado en buena medida por la falta de regulación específica y en términos generales suele atribuírsele un carácter extracontractual. El debate suele girar en torno a la naturaleza del vínculo relacional precontractual, perdiendo de vista la complejidad que supone la negociación y el incumplimiento precontractual. La necesaria interacción con el contrato aconseja su estudio desde la perspectiva del derecho de contratos.

\section{Palabras clave}

Negociación, responsabilidad precontractual, culpa in contrahendo, incumplimiento precontractual, derecho de contratos, PECL.

* $\quad$ Profesor asistente de Derecho Privado de la Universidad de los Andes. Ph. D. y magíster en Derecho de la Responsabilidad. Miembro del Grupo de Investigación de Derecho Privado Contemporáneo de la Universidad de los Andes. Correo electrónico: s.carrenom@uniandes.edu.co. Orcid: https://orcid. org/0000-0003-1102-756X.

Agradezco a los profesores Xabier Basozabal Arrúe y Fernando Gómez Pomar por su tiempo y sus valiosos comentarios. También agradezco los comentarios recibidos en desarrollo del seminario adelantado por el Grupo de Investigación “Derecho Privado Contemporáneo” del área de Derecho Privado de la Universidad de los Andes y de los pares evaluadores. Los errores, por supuesto, son enteramente míos.

** $\quad$ Este texto es un trabajo de investigación producto del Grupo de Investigación de Derecho Privado Contemporáneo de la Universidad de los Andes. 


\title{
Precontractual Liability from a Contract Law perspective
}

\begin{abstract}
Pre-contractual liability has experienced a notable awareness of modern law. Overall, there is agreement over judicial enforcement and damages recovered. Nonetheless, there is no unanimity about culpa in contrahendo's nature. Disagreement arises, mainly, on the absence of specific regulation and most of the legal systems opts for tort solution. The debate focuses on determining the nature of the precontractual relationship regardless of the complexity that underlies negotiation and the breach of the precontractual duties. Needful interaction between contract and negotiations endorses a comprehensive study from a contract law perspective.
\end{abstract}

\section{Keywords}

Negotiation, precontractual liability, culpa in contrahendo, breach of precontractual duties, contract law PECL. 


\section{Introducción}

La responsabilidad precontractual ha ganado notoriedad en el derecho contemporáneo. Pese a tratarse de una figura centenaria pasó relativamente desapercibida hasta finales del siglo XX. En términos generales, parece existir acuerdo sobre su procedencia, sus elementos estructurantes y la extensión del daño ${ }^{1}$.

Su naturaleza, por el contrario, ha sido menos pacífica. El desencuentro viene dado en buena medida por la falta de regulación legal en los códigos decimonónicos. Esta discusión trasciende del ámbito teórico, pues de ello dependerán, por ejemplo, la acción procedente, los plazos de prescripción o la carga de la prueba, en especial en aquellos ordenamientos carentes de una regulación específica.

La discusión suele girar en torno a la naturaleza del vínculo relacional precontractual, lo cual en la práctica ha conducido a que se pierda de vista la complejidad que supone la negociación.

Teniendo esto presente, el artículo pretende profundizar en la complejidad de la negociación y su inescindible relación con el contrato, lo cual invita a abordarlos de forma conjunta tomando como referencia el derecho de contratos. De esta forma se podría dotar de mayor coherencia al sistema y establecer mejores criterios de solución para aquellos incumplimientos precontractuales que pueden proyectarse sobre el contrato mismo.

Para cumplir con los objetivos planteados se analizaron las soluciones provistas en el derecho comparado y en los proyectos de armonización de derechos de contratos. Dicho esto, lo que resta del trabajo se divide en tres secciones. En la primera se presentaran las tres soluciones ofrecidas en el derecho comparado para resolver el problema de la naturaleza del vínculo precontractual y el régimen de responsabilidad que le es aplicable. En la segunda se estudiarán los argumentos que recomiendan un estudio conjunto desde la perspectiva del derecho de contratos. Como complemento, se estudiará la solución ofrecida por los proyectos de armonización que parece decantarse por el modelo de integración. En la última se expondrán las conclusiones.

1 En términos generales, se ha optado por el interés negativo como medida del daño. Pese a ello, existen por lo menos dos pronunciamientos de la Corte Suprema holandesa que han reconocido la procedencia del interés positivo. Corte Suprema holandesa, sentencia Plas vs. Valburg, NJ 1983/723. 


\section{Tres concepciones del vínculo precontractual y el régimen de responsabilidad aplicable}

\section{A) Naturaleza extracontractual basada en deberes genéricos de conducta}

Los seguidores de esta postura basan su planteamiento en la inexistencia de acuerdo. A falta de contrato, la obligación de indemnizar encuentra sustento en la inobservancia del deber genérico de no causar daño a otro (alterum non laedere)2.

Francia

En Francia, la amplitud de la regla general de responsabilidad extracontractual permitió cobijar los supuestos de responsabilidad precontractual. La doctrina ${ }^{3}$, por otra parte, fue muy crítica con la tesis contractualista pues partía de la ficción de que el oferente tenía la intención de asumir el compromiso que se le atribuye al momento de emitir la oferta; tampoco quedaba claro cuáles eran las obligaciones que surgían, teniendo en cuenta que el oferente podía revocar la oferta en cualquier momento.

Siguiendo la solución aquiliana, se requiere la concurrencia de culpa de quien abandona la negociación, y se pone como ejemplo la promoción de inversiones de la contraparte cuando no se tiene una intención firme de contratar ${ }^{4}$. Sin embargo, algunos autores ${ }^{5}$ señalan que esta amplitud ha permitido que se indemnicen los

El fundamento de la responsabilidad extracontractual ha sido muy debatido. La discusión surge de la exigibilidad o no de la antijuridicidad como requisito estructurante. En el derecho alemán, por ejemplo, se exige la lesión de un derecho subjetivo. En España, un sector de la doctrina exige igualmente la antijuridicidad. Por su parte, Pantaleón se opone pues echa en falta un fundamento normativo que la sustente. Sin perjuicio de lo anterior, cuestiona la regla del alterum non laedere como fundamento de la responsabilidad extracontractual por considerarlo una regla etérea que distorsiona la noción de derecho subjetivo -todo y nada podría serlo-. En contraste, Pascual Estevill sostiene que el 1902 encuentra su fundamento en el principio de no injerencia en la esfera del interés del otro que reconduce necesariamente a la regla del alterum non laedere. Lluis Pascual Estevill, Derecho de daños: principios generales, responsabilidad contractual, extracontractual y responsabilidad precontractual (Barcelona: Bosch, 1995), 1088; Fernando Pantaleón, “Comentario al artículo 1902 CC", en Comentarios del Código Civil (Madrid: Ministerio de Justicia, 1993), 1993.

3 Henri Mazeaud y Léon Mazeaud, Traité théorique et pratique de la responsabilité civile [t. I] (Paris: Librairie du Recueil Sirey, 1947), 127 y ss. Générale de Droit y de Jurisprudence, 1930), 175-77. 
perjuicios sufridos durante las negociaciones precontractuales, aun cuando el perjuicio no esté precedido de una falta atribuible al responsable.

Señálese en todo caso que en 2016 se reformó el libro tercero del Código Civil. En lo que aquí interesa, se vino a incluir una regulación expresa de la responsabilidad precontractual en los artículos 1112, 1112-1 y 1112-2. Siguiendo la línea tradicional, mantiene la tesis extracontractual.

\section{España}

En España se adopta esta postura teniendo en cuenta la amplitud del artículo $1902^{[6]}$ del Código Civil que, siguiendo la solución francesa, permite encauzar cualquier daño ocasionado por un comportamiento antijurídico al régimen extracontractual en ausencia de una relación jurídica precedente.

Como complemento, se ha puesto de presente la indeterminación de los deberes que surgen a partir del mandato de buena fe, lo cual impide el nacimiento de una relación jurídica cobijada por el artículo 1101 (responsabilidad contractual) ${ }^{7}$. Dicha ausencia permite deducir que el daño generado en desarrollo de una negociación presupone la violación del deber genérico del alterum non laedere, no el incumplimiento de un "programa solutorio previamente convenido"8.

Italia

En Italia, la responsabilidad precontractual protege la libertad contractual. Por tratarse de un interés inherente a la vida de relación no está supeditado al surgimiento de una relación contractual como condición necesaria para su vulneración. En otras palabras, el comportamiento de las partes durante la negociación no se orienta a la satisfacción de intereses particulares pretendidos por el otro: se trata, más bien, de un comportamiento genérico concordante con la libertad

(2) frente a los perjuicios sufridos durante los ensayos de un automóvil que anteceden a su compra; y (3) respecto de los accidentes laborales sufridos con antelación a la contratación. interviniendo culpa o negligencia, está obligado a reparar el daño causado”. otros ordenamientos (Bilbao: Servicio Editorial, Universidad del País Vasco, 1989), 225 y ss.

Pascual Estevill, Derecho de daños: principios generales, responsabilidad contractual, extracontractual y responsabilidad precontractual, 1083 y ss. Esta postura ha sido compartida mayoritariamente por la jurisprudencia. Entre otras, Tribunal Supremo español, Sala de lo Civil, sentencias Tol 2364, 14 de junio de 1999, Tol 2586, 16 de diciembre de 1999, Tol 2610, 11 de abril de 2000. 
contractual. De ahí que se invoque el artículo $2043^{[9]}$ del Código Civil italiano como fundamento normativo de la responsabilidad, en defecto del $1218^{[10]}$, que regula la responsabilidad contractual.

Para la doctrina ${ }^{11}$, el deber de actuar conforme a la buena fe no se deduce de una relación obligatoria, ni pretende satisfacer intereses individuales específicos. Así pues, la ausencia de contrato reafirma la exigencia de un deber genérico de no dañar a otro, y la responsabilidad precontractual viene tan solo viene a ser una hipótesis más de la transgresión de los deberes genéricos de conducta que de ninguna manera puede equipararse a las obligaciones en sentido propio ${ }^{12}$.

Desde esta perspectiva, la responsabilidad precontractual tutela el interés de no ser envuelto en tratos inútiles, no el cumplimiento de una obligación.

\section{Derecho comunitario europeo}

El Reglamento de Roma II trata a la culpa in contrahendo como evento típico de responsabilidad extracontractual, pese a que le reconoce un régimen especial de competencia $^{13}$. En este sentido el artículo doce establece:

1. La ley aplicable a una obligación extracontractual que se derive de los tratos previos a la celebración de un contrato, con independencia de que el contrato llegue o no a celebrarse realmente, será la ley aplicable al contrato o la que se habría aplicado al contrato si este se hubiera celebrado.

2. Cuando la ley aplicable no pueda determinarse mediante el apartado 1 , la ley aplicable será: (a) la ley del país en el que se haya producido el daño, independientemente del país en el que se haya producido el hecho generador del daño e independientemente del país o países en los que se hayan producido las consecuencias indirectas del hecho en cuestión, o (b) cuando las partes tengan su residencia habitual en el mismo país en

El artículo 2043 del Código Civil italiano dispone: "Cualquier hecho doloso o culposo que cause a otro un daño injusto obligará a quien lo cometió a resarcir el daño". ción debida está obligado a indemnizar el perjuicio sino prueba que el incumplimiento o retardo está determinado por la imposibilidad de la prestación debida por causa no imputable a él".

1 Massimo Bianca, Derecho Civil: El contrato, 2. ${ }^{a}$ ed. (Bogotá: Universidad Externado de Colombia, 2007), 177.

Emilio Betti, Teoria General del Negocio Jurídico (Granada: Comares, 2000), 440; Renato Scognamiglio, Teoría General del Contrato (Bogotá: Universidad Externado de Colombia, 1996), 96.

El Reglamento (CE) n. ${ }^{\circ}$ 864/2007 del Parlamento Europeo y del Consejo del 11 de julio de 2007 relativo a la ley aplicable a las obligaciones extracontractuales ("Roma II"). 
el momento en el que se produjo el hecho generador del daño, la ley de ese país, o (c) si del conjunto de las circunstancias se desprende que la obligación extracontractual que se derive de los tratos previos a la celebración de un contrato presenta vínculos manifiestamente más estrechos con otro país distinto del indicado en las letras $a$ y $b$, se aplicará la ley de este otro país.

En esta línea, el Tribunal de Justicia Europeo en el caso Marconi v. Sinto Maschinenfabrik ${ }^{14}$ ratificó su carácter extracontractual reconociendo que el fundamento de la reparación podía encontrarse en la infracción del deber de actuar conforme a la buena fe durante la etapa precontractual.

\section{Argentina y Colombia}

En Argentina la doctrina se decantó por la naturaleza aquiliana. Algunos se basaron en el ámbito restrictivo de la responsabilidad contractual que solo se predica del incumplimiento de convenios o contratos ${ }^{15}$; otros, en que la exigencia del deber de actuar conforme a la buena fe bien puede explicarse a partir de los deberes genéricos de la vida de relación ${ }^{16}$.

Si bien se reconoce que la responsabilidad precontractual reviste características particulares, se consideró que no ameritaba un trato autónomo. Así las cosas, se acudió al carácter residual del régimen extracontractual que permitía el estudio de cualquier infracción del deber genérico de no causar daño a otro con independencia de su fuente.

Sin embargo, la expedición del nuevo Código Civil y Comercial de la Nación relativiza la cuestión pues optó por un modelo de unificación de la responsabilidad contractual y extracontractual (sin perder de vista algunos matices: por ejemplo, la regla de previsibilidad que sigue vigente para la primera $)^{17}$.

14 Tribunal de Justicia Europeo, sentencia C-334/00 Fonderie Officine Meccaniche Tacconi c/Heinrich Wagner Sinto Maschinenfabrik, 17 de septiembre de 2002.

15 Jorge Mosset Iturraspe, Responsabilidad precontractual (Santa Fe: Rubinzal-Culzoni Editores, 2006), 280; Alejandro Borda, "La buena fe en la etapa precontractual”, Vniversitas 129 (2014): 71, http://dx.doi.org/10.11144/Javeriana.VJ129.Ibfe; Roberto Brebbia, Responsabilidad precontractual (Buenos Aires: Editorial La Roca, 1987), 49. Aires: Abeledo-Perrot, 1992), 48 y ss.

17 Gustavo Caramelo, "Sección 3a. Tratativas contractuales", en Código Civil y Comercial de la Nación Comentado [t. III], ed. Marisa Herrera, Gustavo Caramelo y Sebastián Picasso (Buenos Aires: Infojus, 2015), 394. 
La jurisprudencia colombiana, por su parte, ha optado por la misma solución atendiendo a la ausencia de contrato ${ }^{18}$. En apoyo a esta solución se destaca Arrubla, quien reconoce que el deber de negociar conforme a la buena fe antecede al contrato y, por tanto, escapa de la órbita contractual. En sus palabras, "El fundamento legal de la responsabilidad precontractual es muy claro en el sistema jurídico colombiano con la anotación del artículo 863 y la razón de ser de esta norma resulta obvia, pues mientras no esté formado el contrato, la fuente de responsabilidad no puede ser contrato sino en la transgresión de un deber extraño y anterior al contrato"19.

\section{B) Naturaleza contractual en razón a la existencia de una relación jurídica preexistente}

Los defensores de esta postura pregonan la existencia de una relación jurídica que se construye a partir de la obligación de actuar conforme a la buena fe durante la negociación. En su opinión, los deberes surgidos en este contexto no son concebidos de forma abstracta, sino que, por el contrario, se encuentran circunscritos a condiciones de tiempo, modo y lugar específicos en favor de un sujeto determinado con el que se ha entrado previamente en contacto. Para sus seguidores la responsabilidad precontractual surge del incumplimiento en el marco de una relación preexistente y no de la inobservancia de un deber genérico de comportamiento.

Von Ihering ${ }^{20}$, por ejemplo, reconoce la ineludible relación que existe entre la etapa precontractual y el contrato; en concreto, se refirió al ocultamiento de una causal de nulidad que termina viciando el contrato. En su opinión, la parte incumplidora debía indemnizar los perjuicios causados por el incumplimiento de la "garantía implícita" que nacía con la negociación y le obligaba a actuar diligentemente ${ }^{21}$.

Corte Suprema de Justicia. Sala de Casación Civil. Sentencias 4962, 31 de mayo de 1998, MP: Rafael Romero Sierra y C-5295, 23 de junio de 2000, MP: José Fernando Ramírez Gómez.

19 Jaime Arrubla Paucar, Contratos mercantiles: Teoría General del Negocio Mercantil, 13. ${ }^{a}$ ed. (Bogotá: Legis, 2012), 133-34.

20 En Brebbia, Responsabilidad precontractual, 25 y ss; Stiglitz, Responsabilidad precontractual: incumplimiento del deber de información, 45; José Puig Brutau, Fundamentos de derecho civil [t. II, vol. I] Doctrina General del Contrato (Barcelona: Bosch, 1989), 216; Catalina Salgado Ramírez, "Breve introducción a la responsabilidad precontractual en la teoría de Rudolf von Jhering", en Estudios de Derecho Civil en memoria de Fernando Hinestrosa, t. I. (Bogotá: Universidad Externado de Colombia, 2014), 721-58.

21 En este punto conviene señalar que Von Ihering recurre a las fuentes romanas en especial las referidas a la venta de cosas sagradas, públicas o religiosas para cimentar los contornos de la figura. 
Faggella y Saleilles, por su parte, centraron su atención en la existencia de un acuerdo tácito entre las partes que les obliga a comportarse conforme a la buena $\mathrm{fe}^{22}$.

Ciertamente, la tesis contractualista fue introducida por los autores que construyeron las bases de la responsabilidad precontractual; no obstante, con el paso del tiempo vino a ser desplazada por la tesis aquiliana. En la actualidad, el derecho alemán viene a ser el único ordenamiento que de forma expresa reconoce su naturaleza contractual.

\section{Las obligaciones precontractuales en el derecho alemán}

En Alemania, la responsabilidad precontractual cuenta con reconocimiento normativo a partir de la reforma al libro de las Obligaciones del Código Civil alemán -BGB- de 2002. El nuevo artículo $311^{[23]}$ regula las obligaciones contractuales y análogas en los términos que se transcriben a continuación:

Artículo 311. Obligaciones contractuales y análogas

(1) Con el fin de crear una obligación negocial y para modificar lo contenido en la obligación, es necesario un contrato suscrito entre las partes, salvo otra cosa dispuesta por este Código.

(2) Una obligación con deberes de acuerdo con lo establecido en el artículo 241 -numeral $2^{[24]}$ - también existe por:

El inicio de negociaciones contractuales.

2. La preparación de un contrato donde una de las partes, en aras de establecer una potencial relación contractual, le da a la otra la posibilidad de afectar sus derechos, bienes jurídicos u otros intereses o confiándoselos a ella.

3. Contactos análogos de carácter negocial.

(3) Una obligación con deberes de acuerdo con lo establecido en el artículo 241 -numeral 2- también surge en relación con personas que no pretenden ser partes del contrato. Dicha obligación surge especialmente si el tercero cuando un tercero reclama para sí una confianza especial plimiento del deber de información, 45; Hilsrerand, Las obligaciones precontractuales, 85 y ss. 
y a través de ésta influye considerablemente en las negociaciones del contrato o en su perfeccionamiento ${ }^{25}$.

Aunque su inclusión resulta novedosa, no hizo más que positivar la posición tradicionalmente aceptada en buena medida por la jurisprudencia ${ }^{26}$. Esto no es gratuito, pues el BGB, a diferencia de los códigos civiles de inspiración francesa, regula el régimen extracontractual de forma restrictiva ${ }^{27}$, lo cual impidió que la responsabilidad precontractual pudiera resolverse siguiendo la regla del alterum non laedere.

Así pues, la reforma del 2002 viene a reconocer que con la negociación surge una relación obligatoria negocial análoga a la contractual que obliga, entre otras cosas, a comportarse conforme a las reglas de la buena fe (art. 242) ${ }^{28}$ y respetar los derechos e intereses de la contraparte (art. 241-2) ${ }^{29}$.

\section{Naturaleza contractual como tesis minoritaria}

Como se ha visto, la mayoría de los ordenamientos examinados ha optado por la solución aquiliana; no obstante, subsisten voces críticas en la doctrina.

En el derecho italiano ${ }^{30}$, por ejemplo, se ha señalado que la buena fe impone a los negociantes deberes inter-partes en el marco de una relación jurídica, cuyo incumplimiento debe examinarse a la luz del régimen contractual. De igual manera, se ha resaltado que la obligación de negociar conforme a la buena fe establecida de Justicia en http://www.gesetze-im-internet.de/englisch_bgb/englisch_bgb.html\#p0716 [consultada por última vez, el 23 de abril de 2020, 18:30].

Basil Markesinis, Hannes Unberath y Angus Johnston, The German Law of Contract, 2. a ed. (Oxford and Portland, Oregon: Hart Publishing, 2006); Klaus Albiez Dohrmann, "Un nuevo Derecho de obligaciones. La Reforma 2002 del BGB”, Anuario de Derecho Civil 55, n. ${ }^{\circ} 3$ (2002): 1191, https:// www.boe.es/publicaciones/anuarios_derecho/abrir_pdf.php?id=ANU-C-2002-30113301228.

El artículo 823 del BGB limita la aplicación de la responsabilidad aquiliana a la afectación de los bienes jurídicos enunciados a saber: vida, integridad física, salud, libertad y propiedad, siempre que no se trate de pérdidas puramente económicas.

Reinhard Zimmermann y Simon Whittaker, "Good Faith in European Contract Law: Surveying the legal Landscape", en Good faith in European Contract law, editado por Reinhard Zimmermann y Simon Whittaker (Cambridge: Cambridge University Press., 2000), 24.

Este artículo reconoce dos tipos de obligaciones: una positiva, entendida como el cumplimiento de la prestación debida y una negativa o de protección que impone el deber de no perjudicar los intereses del otro. Esta segunda, como señalan Markesinis y Unberath, se trata de una obligación general que se deben mutuamente las partes y pretende el respeto de los derechos e intereses de la contraparte que surgen de la relación obligacional; siguiendo esta distinción, la jurisprudencia colombiana ha reconocido la existencia de deberes primarios y secundarios de conducta. Markesinis, Unberath y Johnston, The German Law of Contract, 127 y ss. 
en los artículos $1337^{[31]}$ y $1338^{[32]}$ del Código Civil italiano no presenta diferencias sustanciales con la buena fe contractual.

En similar sentido se han referido las voces críticas en el derecho español ${ }^{33}$ que consideran que la existencia de una relación o "contacto social" impone a las partes deberes concretos. Para ellas, el artículo 1902 del Código Civil español resulta vago para proteger la buena fe, por ello se decantan por la protección más concreta que ofrece el régimen contractual teniendo en cuenta la identidad de la buena fe en la etapa precontractual y contractual.

\section{La paradoja del caso colombiano}

La jurisprudencia nacional se ha decantado por la tesis aquiliana. Pese a ello, la doctrina parece preferir una solución contraria, aunque no puede decirse que sea una posición unánime ${ }^{34}$. Veamos algunos ejemplos:

Santos Ballesteros ${ }^{35}$ reconoce que la buena fe prohíbe comportamientos abusivos durante la negociación. Esta prohibición, a su juicio, se concreta en una obligación de no hacer y deberá resolverse conforme a las reglas propias del régimen contractual, en especial el artículo 1612 del Código Civil.

Por otra parte, critica la solución adoptada por la jurisprudencia pues la considera ambigua. En su opinión es contradictorio que la Corte Suprema deduzca una responsabilidad extracontractual pese a reconocer "la existencia de un conjunto de relaciones y contactos entre las partes"36. Tampoco es claro por qué aplica el

El artículo 1337 del Código Civil italiano dispone que "Las partes en el desarrollo de las negociaciones y en la formación del contrato deben comportarse de acuerdo con la buena fe".

El artículo 1338 del Código Civil italiano dispone: "La parte que conociendo o debiendo conocer la existencia de una causa de invalidez del contrato no lo ha comunicado a la otra está obligado a reparar el daño que ésta ha sufrido por haber confiado, sin su culpa, en la validez del contrato".

Puig Brutau, Fundamentos de derecho civil [t. II, vol. I] Doctrina General del Contrato, 216. Alonso Pérez, con cierto escepticismo, también se remite al régimen contractual. En su opinión, la obligación de indemnizar surge del "quebrantamiento de la lealtad y la confianza que las partes se deben por el hecho de entrar en un contacto negocial" que presenta similitud con las relaciones contractuales. Mariano Alonso Pérez, "La responsabilidad precontractual", Revista Crítica de Derecho Inmobiliario 485 (1971): 891 y ss.

Como se vio, Arrubla prefiere la solución aquiliana. Rengifo, por su parte, prefiere la solución autonomista pues considera que existe una relación jurídica preparatoria de origen legal. Finalmente, Oviedo Albán no adopta una postura inequívoca, pero parece sumarse a la tesis contractualista. Mauricio Rengifo Gardeazábal, La formación del contrato (Bogotá: Universidad de los Andes Editorial Temis, 2016), 275 y ss.; Jorge Oviedo Albán, "Tratos preliminares y responsabilidad recontractual", Vniversitas 115 (2008): 108 y ss. Javeriana, 2008), 227 y ss. 
artículo 1602 a la negociación como derrotero de la libertad y de respeto de la autonomía privada, si es propio del régimen contractual. En sus palabras, "[a]sí pues no puede dejarse de lado, como lo he reiterado, la presencia de una relación vinculante en los tratos preliminares y, si las cosas son así, como en efecto lo son, no puede sostenerse válidamente que la buena fe exenta de culpa que alude el artículo 863 del Código de Comercio sea un deber genérico, sino, por el contrario, concreto y determinado, lo que da origen a una arquetípica responsabilidad contractual, muy a pesar de lo que sostiene la Corte" ${ }^{\prime 37}$.

Monsalve ${ }^{38}$, por su parte, hace hincapié en que la buena fe impone a las partes deberes concretos como son el respeto de la confianza legítima nacida en el otro y la promoción y satisfacción de sus expectativas durante las negociaciones. Estos deberes, a su juicio, imponen a las partes la realización de intereses ajenos, lo cual en la práctica supone el cumplimiento de prestaciones específicas que se diferencian del deber genérico de no causar daño a otro que solo se expresa en sentido negativo (no irrogar daños a otros). De igual manera, critica la remisión que suele hacerse a los fundamentos extracontractuales por considerar que éstos se encuentran ligados con deberes absolutos que desbordan las relaciones específicas que surgen con la negociación y desconocen el contacto requerido entre las partes para el nacimiento de la obligación precontractual.

Finalmente, Bernal Fandiño ${ }^{39}$ reconoce la posible concurrencia de los regímenes contractual y extracontractual en la responsabilidad precontractual; pese a ello, considera que resulta más favorable optar por el régimen contractual teniendo en cuenta que los sujetos están determinados, entre ellos ha surgido una relación concreta y tienen la intención (no la obligación) de suscribir un contrato específico.

\section{C) Naturaleza autónoma ante la imposibilidad de encuadrarla en los regímenes existentes}

Los seguidores de esta postura ponen de manifiesto la dificultad que entraña la equiparación de la responsabilidad precontractual con los regímenes existentes. En su opinión, optar por uno u otro régimen no garantiza la cabal protección de

38 Vladimir Monsalve Caballero, Responsabilidad precontractual: la ruptura injustificada de las negociaciones, 338 y ss. (Ibáñez, Bogotá, 2010).

39 Mariana Bernal Fandiño, "La naturaleza jurídica de la responsabilidad civil derivada de la inobservancia de los deberes colaterales de conducta”, Vniversitas 126 (2013): 52 y ss., https://revistas. javeriana.edu.co/index.php/vnijuri/article/view/6120.
} 
los afectados porque la solución del caso concreto siempre habrá de realizarse con base en un régimen inaplicable.

Algunos se apoyan en la existencia de un "contrato tácito" que tiene lugar con el inicio de la negociación; a falta de consentimiento se asimila al cuasicontrato y su fuente deviene de la ley o de la equidad ${ }^{40}$. Otros reivindican la defraudación de la confianza y la violación de los deberes secundarios de protección por parte de los negociantes como fundamento de la responsabilidad precontractual. Desde esta perspectiva, la ausencia de contrato y la imposición de deberes positivos de conducta (extraños al régimen extracontractual) impiden asimilarla con los regímenes existentes ${ }^{41}$. Otros más recurren al abuso del derecho teniendo en cuenta que la ruptura injusta de la negociación supone la extralimitación en el ejercicio del derecho de no contratar que afecta el interés de la confianza de la parte perjudicada, quien no cuenta con específica prerrogativa normativa que lo proteja ${ }^{42}$.

\section{Una concepción más amplia de la responsabilidad precontractual que transcienda del vínculo relacional}

Como se ha visto, la discusión ha girado en torno a la naturaleza del vínculo relacional precontractual y se ha perdido de vista la complejidad de la negociación. En efecto, la negociación solo se explica en una relación de medio a fin con el contrato, pues en ella se recolecta e intercambia información que les permite a las partes establecer la viabilidad de la operación y los términos más eficientes para contratar $^{43}$. Sus consecuencias, por tanto, pueden percibirse en el contrato.

Así las cosas, el iter contractual debe abordarse como un fenómeno complejo e interrelacionado. Por ello, resulta inconveniente establecer un tratamiento

Catalina Salgado Ramírez, "Consideraciones históricas acerca de la responsabilidad precontractual antes de Rudolf von Jhering. Aproximación doctrinal”, Revista de Derecho Privado, n. ${ }^{\circ} 22$ (2012): 291 y ss., https://revistas.uexternado.edu.co/index.php/derpri/article/view/3196.

41 Dieter Medicus, Tratado de las relaciones obligaciones (Barcelona: Bosch, 1995), 64-65.

42 María Paz García Rubio, La responsabilidad precontractual en el derecho español (Madrid: Tecnos, 1991), 131 y ss.

43 Avery W. Katz, "When should an offer stick? The Economics of Promissory Estoppel in Preliminary Negotiations", The Yale Law Journal 105 (1996): 1267, https://scholarship.law.columbia.edu/ faculty_scholarship/266. 
desligado para fenómenos interdependientes, máxime cuando las partes están obligadas a actuar conforme a la buena $\mathrm{fe}^{44}$.

Esta exigencia no cambia en la negociación, de hecho, se acrecienta, pues son los deberes precontractuales los que vienen a establecer las pautas de comportamiento que las partes habrán de seguir durante el proceso. Si bien es difícil establecer un catálogo rígido de comportamientos permitidos y prohibidos, el alcance de estos deberes puede concretarse atendiendo a las circunstancias que acompañan el caso y a los estándares de conducta que "permiten evaluar la conformidad de una conducta frente al modelo propuesto por el estándar"45.

En este sentido, debe señalarse que la aludida amplitud no es un criterio suficiente para equiparar los deberes precontractuales con los deberes generales de abstención (propios del régimen extracontractual), pues los primeros surgen en favor de un sujeto determinado (el otro negociante) a partir del primer contacto; los segundos, por el contrario, están orientados a toda la colectividad. Tampoco puede perderse de vista que la vaguedad es un recurso común en la redacción de los contratos, especialmente en aquellos supuestos donde resulta difícil o en extremo costoso definir una medida específica de cumplimiento ${ }^{46}$; en estos casos, se deja en manos de un tercero su evaluación haciendo uso de los estándares de conducta.

El criterio diferenciador, por tanto, viene dado por la finalidad perseguida por la norma. ¿Se pretende proteger a un sujeto determinado o a la colectividad en general? En el primer caso, los deberes precontractuales deberían regirse por el régimen contractual; en el segundo, debería optarse por la responsabilidad aquiliana.

Se discute si ha de tenerse como un deber -asociado con aquellos estándares generales de comportamiento que acompañan al contrato- o como una obligación -las prestaciones (contenido económico) expresamente convenidas que tienen en cuenta las particularidades del contrato-. Pese a la controversia, se habla de ella indistintamente. Esto no sorprende teniendo en cuenta que en la práctica el deber y la obligación suelen emplearse como sinónimos intercambiables y hacen referencia a aquello que es debido -deberes implícitos o por previsión expresa en el contrato-. El uso indistinto puede comprobarse en los proyectos de armonización - por ejemplo, PECL y DCFR-, en las convenciones internacionales - por ejemplo, la CISG-, en el derecho comunitario europeo e incluso en el common law. Bénédicte Fauvarque-Cosson y Denis Mazeaud, European Contract Law: Material for a Common Frame of Reference (Munich: European Law Publishers, 2008), 40-52.

45 Martha Neme Villarreal, "La buena fe es un principio que se expresa mediante cláusulas generales cuya reiterada aplicación tiene por virtud generar estándares de conducta", en Jornadas FrancoColombianas "Los grandes estándares del derecho francés", 2012, 14. En esta misma línea, el Tribunal Supremo español, sentencia RJ 1997/3668, 3 de mayo de 1997, ha reconocido la conveniencia de recurrir a los modelos de conducta como medida de cumplimiento teniendo en cuenta que la adecuada valoración de la conducta exige tomar en consideración del entorno social en el que se desenvuelven las partes.

46 Robert E. Scott y George G. Triantis, "Anticipating litigation in contract design", Yale Law Journal 115, n.o 4 (2006): 818 y ss., https://www.yalelawjournal.org/pdf/339_a5pzok3k.pdf. 
En este escrito se entiende que los deberes precontractuales buscan proteger a un sujeto determinado (aquel que entra en la negociación) y por tal motivo se prefiere el régimen contractual.

Sin perjuicio de lo anterior, existen consideraciones adicionales que recomiendan un estudio conjunto de la negociación y el contrato (por lo menos en cuanto a reglas procedimentales se refiere) que suelen pasarse por alto cuando se estudia la cuestión, y se estudiarán a continuación.

\section{A) La confluencia del período contractual y del precontractual en el derecho de contratos}

La definición de la naturaleza de la responsabilidad precontractual tiene incidencia práctica en cuanto a las reglas de prescripción, la acción incoada y la carga de la prueba, que no pueden ser desconocidas. Sin embargo, en un plano más teórico parece haber consenso en que la buena fe y la libertad contractual cumplen un papel preponderante en la negociación, con independencia del régimen escogido.

Desde esta perspectiva, se aboga por una comprensión más amplia de la responsabilidad contractual, que trascienda del contrato como criterio determinante y centre su atención en el derecho de contratos como factor de atribución. En otras palabras, la responsabilidad contractual debe encargarse de resolver las controversias surgidas en el marco de una relación regida por el derecho de contratos.

En efecto, el contrato ha dejado de ser una mera fuente de obligaciones $y$, como señala Gómez Pomar, "son la expresión más importante de articulación de la cooperación entre los individuos [...] las obligaciones expresan los efectos jurídicos de la cooperación humana expresada en un contrato [...] el contrato es sustancial, la obligación es instrumental"47.

Así pues, el derecho de contratos ha de adaptarse a este nuevo rol del contrato y debe regularlo como un fenómeno complejo que trasciende de la relación contractual. Si bien el incumplimiento contractual ${ }^{48}$ y los remedios disponibles frente a él mantienen un lugar preponderante, el derecho de contratos no se agota

Fernando Gómez Pomar, "El incumplimiento contractual en Derecho español", InDret 3 (2007): 4, https://www.raco.cat/index.php/InDret/article/view/78949/103090. En consonancia con lo anterior, la literatura le atribuye funciones adicionales, por ejemplo, la movilización eficiente de recursos hacia usos que generen mayor valor; la promoción de la cooperación entre las partes, la asignación de riesgos futuros; la creación, modificación o extinción de relaciones obligatorias, la promoción de mecanismos informales de cumplimiento. 
ahí. También le interesa el periodo precontractual, el periodo poscontractual y el cumplimiento ordinario del contrato.

Se insiste, existe una relación inescindible entre la etapa precontractual y la contractual porque en la primera se definen los términos materiales del acuerdo; también sirve como criterio interpretativo.

Esta relación, por ejemplo, se hace más explícita cuando se aborda el error como vicio de consentimiento por la información suministrada por la contraparte. En este supuesto, la parte perjudicada se encuentra frente a una disyuntiva: demandar el incumplimiento del deber de información (deber precontractual) que daría lugar al resarcimiento de los daños causados por la celebración de un contrato invalido imputable a la contraparte ${ }^{49}$ o demandar el incumplimiento del contrato por la no conformidad de lo ejecutado con los términos ofrecidos en la etapa precontractual, lo cual daría pie a los remedios contractuales ordinarios ${ }^{50}$.

Un segundo ejemplo que se ha venido desarrollando en Colombia es el de la nulidad del contrato por actos de corrupción acaecidos en el periodo precontractual (objeto ilícito) que también podría dar lugar a la misma disyuntiva ${ }^{51}$.

Sin perjuicio de lo anterior, no son pocas las voces que sugieren la prevalencia de los remedios contractuales, teniendo en cuenta que los efectos pueden proyectarse sobre el contrato mismo. En este sentido se expresa Morales cuando afirma que

[E]l incumplimiento de los deberes precontractuales ha tenido y continúa teniendo tratamiento jurídico precontractual canalizado a través del dolo, el error o la culpa in contrahendo, con efectos también diversos. Pero este tratamiento no es el más adecuado, cuando la información precontractual se proyecta sobre el objeto o contenido del contrato y genera problemas de incumplimiento. Lo más razonable en estos casos es atraer a la responsabilidad contractual tanto la lesión del interés de cumplimiento como la del interés de integridad [...] esta atracción se justifica porque es en el marco de la relación contractual en el que estos daños se producen ${ }^{52}$.

Teresa Rodríguez de las Heras Ballell, “La etapa precontractual en la contratación mercantil”, en Estudios sobre el futuro código mercantil: libro homenaje al profesor Rafael Illescas Ortiz, editado por María José Morillas Jarillo, María del Pilar Perales Viscasillas y Leopoldo José Porfirio Carpio (Getafe: Univerdidad Carlos III, 2015), 1812.

María Paz García Rubio, "La responsabilidad precontractual en la propuesta de modificación del derecho de obligaciones y contratos", Anuario de Derecho Civil LXIII (2010): 1640, https://www.boe. es/publicaciones/anuarios_derecho/abrir_pdf.php?id=ANU-C-2010-40162101642; Gómez, “El incumplimiento contractual", 7.

51 Centro de Arbitraje y Conciliación de la Cámara de Comercio de Bogotá, Laudo Arbitral Concesionaria Ruta del Sol SAS vs. Agencia Nacional de Infraestructura del 6 de agosto de 2019.

52 Antonio Manuel Morales Moreno, Incumplimiento del contrato y lucro cesante (Cizur Menor [Navarra]: Civitas Thomson Reuters, 2010), 90. 
Esta solución también parece haber sido acogida en el derecho de consumo. En el derecho comunitario europeo, por citar un caso, la directiva 1999/44/EC establece por vía negativa que la conformidad del contrato se determina con base en lo contenido en el acuerdo y en las declaraciones previas realizadas por el vendedor. Desde esta perspectiva, las declaraciones precontractuales vinculan al productor o al proveedor y podrán alegarse a través del incumplimiento de contrato.

Las propuestas de directiva para los contratos por internet y venta a distancia ${ }^{53}$ y para la provisión de contenido digital ${ }^{54}$ de 2015 , por su parte, resuelven de forma expresa la cuestión. En ambas propuestas se reconoce que la conformidad contractual viene dada no solo por lo contenido en el contrato sino por los atributos ofrecidos por el vendedor en la etapa precontractual ${ }^{55}$. En consecuencia, habrá incumplimiento cuando el bien vendido o el contenido digital proveído no sean conformes con los atributos anunciados por el vendedor en el período precontractual.

En España, por citar un segundo caso, el Real Decreto legislativo 1/2007 ${ }^{[56]}$ (TR LGDCU) prescribe que al contrato se integran el contenido de la oferta, las promociones y cualquier tipo de publicidad realizada por el vendedor, y la conformidad se establece a partir de lo dispuesto en su conjunto. Así pues, no son extraños los pronunciamientos jurisprudenciales que estudian el desconocimiento de las garantías ofrecidas o de los atributos publicitados en la etapa precontractual por la vía incumplimiento de contrato ${ }^{57}$.

Lo anterior pone de manifiesto la complejidad del incumplimiento precontractual teniendo en cuenta que sus efectos pueden repercutir tanto en la negociación como en el contrato, lo cual, sin duda, reafirma la necesidad de estudiarlo desde una perspectiva comprehensiva. Esta confluencia, se insiste, no supone la equiparación de la negociación con el contrato, si se tiene en cuenta que en cada uno nace de un vínculo jurídico independiente. En este sentido, no es casual que los códigos más recientes (por ejemplo, Holanda, Portugal, Alemania, Francia y Argentina) regulen la negociación de forma independiente y propongan un catálogo limitado de remedios en comparación con el contrato.

COM (2015) 635, final.

Ibíd., 634, final.

Artículos 4.1.c, COM (2015) 635, final y 6.1.a COM (2015) 634, final.

Artículo 61, Real Decreto legislativo 1/2007.

Entre otras, sentencias del Tribunal Supremo del 26 de junio de 1999, 15 de junio de 2000 y 23 de mayo de 2003. 
Esta visión comprensiva también resulta patente en los proyectos de armonización que proponen atraer la responsabilidad precontractual al derecho de contratos. Los Principios de Derecho Europeo de Contratos (PECL), por ejemplo, recomiendan expresamente su aplicación a los supuestos de responsabilidad precontractual, aunque reconocen que algunos sistemas nacionales prefieren estudiarlos bajo las reglas de la responsabilidad extracontractual ${ }^{58}$. En igual sentido se pronuncia la Comisión redactora del Draft Common Frame of Reference (DCFR), que señala que la regulación específica contenida en el libro segundo (capítulo II.3, "Deberes de información y negociación") ofrece un camino más sencillo para hacer frente al incumplimiento de los deberes precontractuales, en comparación con las reglas generales de la responsabilidad extracontractual (libro sexto) ${ }^{59}$.

Teniendo esto de presente, en el siguiente acápite se estudiará con mayor detalle el modelo de confluencia propuesto en los PECL complementada con las soluciones adoptadas en los DCFR y los Principios Unidroit (2016).

\section{B) La responsabilidad precontractual en los Principios del Derecho Europeo de Contratos (PECL)}

Como se vio, los PECL se decantan decididamente por la integración de la responsabilidad precontractual en el derecho de contratos. Tal vez el rasgo más llamativo que tienen los PECL es el de distinguir el incumplimiento en la negociación del incumplimiento de los deberes de información. El primero lo regula en una sección independiente, en la etapa de formación del contrato, y el segundo lo estudia desde la perspectiva de la validez del contrato (como un supuesto de error) ${ }^{60}$.

\section{La responsabilidad en la negociación}

Siguiendo la tradición, Los PECL reconocen dos premisas generales que gobiernan la negociación: (1) Las partes son libres para comenzar una negociación y para

58 Comentarios al artículo 1:101 y 2:301 en Ole Lando y Hugh Beale, Principles of European contract law. Parts I and II, combined and revised, editado por Ole Lando y H. G. Beale (The Hague: Kluwer Law International, 2000), 97 y 190.

59 Comentarios al artículo II-3:501 en Christian von Bar y Eric Clive, Principles, definitions and model rules of European private law: Draft Common Frame of Reference (DCFR) Full Edition (Munich: Sellier, 2009), 262. Como se indicó unas líneas atrás, el Tribunal de Justicia de la Unión Europea, en contraste, reconoce la aplicación del Tratado de Roma II en los supuestos precontractuales. Fonderie Officine Meccaniche Tacconi c/Heinrich Wagner Sinto Maschinenfabrik GmbH (HWS). Sentencia del 17 de septiembre de 2002, C-334/00.

60 Señálese que, en este segundo supuesto, los PECL reconocen la posibilidad de elegir entre los remedios contractuales y los precontractuales. 
retirarse; (2) Las partes deben negociar conforme a las reglas de la buena fe. A partir de estas premisas se ha establecido una regla según la cual cualquier conducta estará permitida en tanto se respete la buena fe. A diferencia de los códigos que regulan expresamente la materia, los Principios recogen dos supuestos básicos de responsabilidad durante la negociación ${ }^{61}$ :

(a) La negociación contraria a la buena fe (artículo 2:301).

(b) El incumplimiento al deber de confidencialidad (artículo 2:302).

Esta aproximación es compartida por los Principios Unidroit (2016) en sus artículos 2.1.15 y 2.1.16 y el DCFR, con un matiz frente al deber de información, en sus artículos II.3:301 y 3:302.

\section{- La responsabilidad por las negociaciones contrarias a la buena fe}

Siguiendo las pautas señaladas, el artículo 2:301 establece la responsabilidad de aquel que negocie contrariando la buena fe o que interrumpe la negociación de forma injustificada. En concreto reconoce tres supuestos generales: (1) cuando se entra en una negociación sin interés real de contratar; (2) cuando se mantiene artificiosamente la negociación; (3) cuando ésta se abandona injustamente.

Aunque no se dice expresamente, la ruptura injusta (supuesto 3 ) exige como punto de partida la defraudación de una situación de confianza. En esencia, se protege la apariencia jurídica en estados avanzados de la negociación ${ }^{62}$ como fórmula intermedia para conciliar los principios de libertad contractual y buena $\mathrm{fe}^{63}$.

Este requisito, por el contrario, no parece seguirse en los supuestos 1 y 2 , según se desprende de los comentarios al artículo 2:301 ${ }^{[64]}$, pues en estos supuestos la responsabilidad vendría dada por el propósito de recabar información de forma desleal ${ }^{65}$. A manera de ejemplo, los comentaristas proponen el siguiente caso para

61 Este modelo ha sido replicado en el nuevo Código Civil y Comercial argentino (artículos 991 y 992) y en los Principios Latinoamericanos de Contratos (artículos 10,11 y 12).

62 La jurisprudencia española entiende, por ejemplo, que el estado avanzado de la negociación puede inferirse con la emisión de una oferta. Tribunal Supremo español, sentencias Tol 2364, 14 de junio de 1999, RJ 2007/6811, 9 de octubre de 2007 y RJ 2011/7400, 15 de octubre de 2011. acompañan su ejercicio en el derecho privado", Revista de Derecho Privado, n. ${ }^{\circ} 36$ (2019): 235, https://doi.org/10.18601/01234366.n36.08.

64 Comentarios al artículo 2:301 en Lando y Beale, Principles of European contract law. Parts I and II, combined and revised, 190-91.

65 El ejemplo propuesto para el primer caso, A tiene la intención de entrar en el mercado donde actúa $B$ y le manifiesta su interés de convertirse en agente de ventas de $B$, buscando recabar información que le servirá para entrar como competidor en el mercado. En el segundo ejemplo, siendo los 
el primer supuesto: A tiene la intención de entrar en el mercado donde actúa B y le manifiesta su interés de convertirse en agente de ventas de $B$, buscando recabar información que le servirá para entrar en el mercado como competidor. Para el segundo supuesto se propone un matiz: $B$ es quien se pone en contacto, pero $A$ continúa negociando para aprender más sobre el mercado y el negocio de $\mathrm{B}$.

Los principios Unidroit, por su parte, mantienen la distinción propuesta en los PECL, pero las hipótesis planteadas en sus comentarios oficiales parecen seguir la fórmula tradicional y protegen la confianza razonable. En el primero caso, $\mathrm{A}$ adelanta con $\mathrm{B}$ una negociación por un tiempo considerable con el único propósito de prevenir que $C$ (su competidor) adquiera el negocio. Tan pronto $C$ cierra una operación alternativa, A abandona la negociación. En el segundo caso, A mantiene con una oficina bancaria una extensa negociación en la que se busca definir las condiciones en que se otorgará un crédito. En el último momento, el director de la oficina le informa a A que no estaba autorizado para otorgar ese crédito y que la oficina central decidió no concederlo.

\section{- Incumplimiento al deber de confidencialidad}

Los PECL, el DCFR y los principios Unidroit, de forma acertada, evitan consagrar un deber general de confidencialidad, lo cual parece lógico teniendo en cuenta que durante la negociación también se intercambia información pública o que también suele ser entregada a terceros. Sin embargo, reconocen el valor de cierto tipo de información que debe ser preservada por el receptor y no puede aprovecharse de forma indebida.

Si bien el artículo 2:302 no define cuándo la información es confidencial, la Comisión redactora en sus comentarios ${ }^{66}$ reconoce dos supuestos en los que nace el aludido deber: (1) cuando se hace alusión expresa al carácter confidencial de la información entregada; (2) cuando del contenido de la información o de las circunstancias en que se obtiene parece razonable entender que se debe tratar como información privilegiada. En este caso surge un deber implícito de conservación teniendo en cuenta que la parte receptora conoce o debía conocer su carácter confidencial.

Debe señalarse que, en todo caso, el incumplimiento del deber de reserva procede con independencia del resultado de la negociación, distinguiéndose así de

mismos sujetos, es B quien se pone en contacto con A. En este caso, continúa negociando para aprender más sobre el mercado y el negocio de B. 
los supuestos típicos de responsabilidad precontractual que parten de la frustración de la negociación.

\section{- Remedios disponibles frente a los incumplimientos precontractuales}

Como se ha dicho, los PECL regulan de forma independiente los remedios precontractuales y se decantan, principalmente, por los remedios monetarios.

En este punto debe hacerse una precisión: tradicionalmente se han reconocido dos medidas de daño el interés positivo (o de la expectativa) y el interés negativo (o de la confianza). Con el primero se pretende situar al actor en la misma situación de utilidad en la que se encontraría de haberse cumplido la prestación; con el segundo, devolver al demandante al estado anterior -como si no se hubiera celebrado el contrato o no se hubiera realizado la negociación ${ }^{67}$.

Ciertamente, el interés positivo es la medida usual en tratándose del incumplimiento contractual; no obstante, en ocasiones es aconsejable recurrir al interés negativo. Por ejemplo, cuando es imposible cuantificar la ganancia esperada por el actor o cuando esto supone un resultado intrínsecamente más justo. En la responsabilidad precontractual, por el contrario, se prefiere el interés negativo porque no se puede condenar al cumplimiento de una promesa que nunca se realizó y, por ello, resulta aconsejable rembolsar los gastos infructuosamente realizados durante la negociación ${ }^{68}$. Con todo, la elección de una u otra medida no se deriva de una exigencia legal que prescriba a priori un interés determinado, sino que corresponde más a un problema de causalidad ${ }^{69}$.

Dicho esto, los tres proyectos de armonización mantienen la aproximación tradicional y reconocen al interés negativo como medida del daño. Sin perjuicio de lo anterior, debe señalarse que los principios Unidroit no descartan la posibilidad de reclamar el interés positivo ${ }^{70}$.

El incumplimiento del deber confidencialidad, no obstante, ha tomado un camino distinto. En todos los proyectos se reconoce que el interés negativo puede ser insuficiente para proteger a la parte perjudicada, por ello extienden la medida del daño a la restitución de los beneficios injustamente obtenidos por la parte

Fernando Gómez Pomar, Previsión de daños, incumplimiento e indemnización (Madrid: Civitas, 2002), 40-41.

Charles Fried, Contract as promise: a theory of contractual obligation (Cambridge, Mass.: Harvard University Press., 1981), 21. hendo", Revista Crítica de Derecho Inmobiliario, 628 (1995): 759-60, https://dialnet.unirioja.es/ servlet/articulo?codigo $=34295$. 
incumplidora (disgorgement interest en el common law) ${ }^{71}$. En esta hipótesis, los proyectos de armonización aplican una solución similar a la desarrollada en las infracciones de la propiedad industrial y los derechos de autor ${ }^{72}$.

Esta fórmula también ha sido adoptada por el Código Civil y Comercial argentino en su artículo 992 y en la Directiva (CE) 2016/943, que establece el régimen de protección para el know-how y demás secretos empresariales, pues en su artículo 14 recurre a la fórmula de indemnización establecida en la Directiva (CE) 2004/48 (protección de los derechos de propiedad intelectual) que le permite a la parte perjudicada optar por las consecuencias negativas de la infracción (que incluye expresamente los beneficios obtenidos por el infractor) o por la regla de las regalías hipotéticas.

En resumen, los supuestos típicos de responsabilidad precontractual están cobijados por el interés negativo o de confianza que incluye los gastos realizados durante la negociación y la pérdida de oportunidad de contratar con terceros ${ }^{73}$ y descarta de forma expresa la procedencia del interés de cumplimiento (artículo 9:502). En contraste, el incumplimiento del deber de confidencialidad permite extender la medida del daño a cualquier daño sufrido por la parte afectada y a los beneficios obtenidos por la parte incumplida.

\section{La responsabilidad por el incumplimiento de los deberes de información}

Los deberes precontractuales de información, por el contrario, son descritos en el capítulo que regula la validez del contrato. Esta clasificación no es casual, es el resultado de la especialización de los deberes de información. Como se indicó, el incumplimiento de los deberes de información puede proyectarse en el consentimiento de las partes y en el objeto del contrato; sin embargo, se origina en la etapa precontractual. La necesidad de tomar decisiones conscientes, especialmente en contextos donde prima la asimetría de la información, ha motivado la imposición de exigencias concretas sobre el contenido de la información que se provee en el

71 Richard R. W. Brooks, "The Efficient Performance Hypothesis", The Yale Law Journal, 116 (2006): 577 y ss., https://digitalcommons.law.yale.edu/ylj/vol116/iss3/2; E. Allan Farnsworth, "Your Loss or My Gain? The Dilemma of the Disgorgement Principle in Breach of Contract", Yale Law Journal 94, n. ${ }^{\circ} 6$ (1985): 1339, https://digitalcommons.law.yale.edu/ylj/vol94/iss6/4.

72 Comentarios al II-3:302 DCFR, que sigue la regla del artículo 2:302 del PECL, en Bar y Clive, Principles, definitions and model rules of European private law: Draft Common Frame of Reference (DCFR) Full Edition, 254.

73 Sin embargo, los PECL guardan silencio frente a las negociaciones artificiosas contempladas en 2:301. La duda surge en la medida en que a éstos podría aplicárseles el artículo 2:302 por el aprovechamiento indebido de la información recibida. 
marco de una negociación. Si bien ha tenido mayor impacto en el derecho de consumo, no es ajeno al derecho de contratos.

EI DFCR también reconoce los deberes de información, sin embargo los desarrolla en la sección de los deberes precontractuales ${ }^{74}$.

Dicho esto, los PECL estudian el incumplimiento de los deberes de información desde una perspectiva dual, como problema de consentimiento -precontractual- y como supuesto de incumplimiento de contrato ${ }^{75}$. Por cuestiones de la materia este trabajo se concentrará en el primero. Algunos comentarios sobre la propuesta:

\section{- Error fundamental}

El error es un vicio de consentimiento que, en ocasiones, puede ser imputable a la contraparte. El artículo 4:103 establece tres supuestos de anulabilidad por error cuando: (1) media error por la información entregada por la contraparte; (2) el error siendo conocido por la contraparte o debiendo conocerlo no se corrigió; (3) es un error mutuo. En los dos primeros supuestos se presentará el incumplimiento de los deberes de información.

Con todo, el incumplimiento no es suficiente para invalidar el contrato: se requiere que además haya causado una disparidad relevante entre aquello que se quería contratar y aquello que se terminó contratando. En otras palabras, el error ha de ser fundamental en la decisión de la parte equivocada, a tal punto que, de no existir, la parte afectada no habría celebrado el contrato o lo habría celebrado en condiciones distintas de las pactadas. En esta hipótesis los PECL reconocen la anulación del contrato -con la consecuente restitución-y la indemnización de los daños y perjuicios conforme a lo dispuesto en el 4:117.

Un aspecto novedoso de la propuesta consiste en la posibilidad que le asiste al afectado de mantener el contrato y reclamar los daños sufridos por el incumplimiento ${ }^{76}$.

74 Como posible explicación podría aludirse el mayor alcance que se pretende con el Draft en la medida en que procura regular de forma conjunta los contratos B2B y B2C. Desde esta perspectiva, el deber de información despierta particular interés en las relaciones de consumo (B2C) atendiendo a la asimetría de información presente y, por ello, propende por establecer un contenido mínimo de información que permita a los consumidores tomar decisiones informadas y condiciona la validez del contrato al consentimiento informado.

75 Comentarios al artículo 4:103 en Lando y Beale, Principles of European contract law. Parts I and II, combined and revised, 231.

76 Al respecto, Antonio Manuel Morales Moreno, “¿Es posible construir un sistema precontractual de remedios? Reflexiones sobre la propuesta de modenización del derecho de obligaciones y contratos en el marco del derecho europeo", en Derecho privado europeo y moderninización del derecho contractual en España, editado por Klaus Albiez Dohrmann (Barcelona: Atelier, 2011), 411. 


\section{- Error no fundamental}

Conforme a lo dispuesto en el artículo 4:106, la anulación no procederá cuando el error no es fundamental. Sin embargo, permite la reparación de los daños causados a quien celebró el contrato confiando en la información incorrecta entregada por la contraparte.

\section{- Medida del daño}

El artículo 4:117 establece que la medida del daño en ambos supuestos -error fundamental y no fundamental- viene dada por el interés de la confianza, toda vez que la información defectuosa no causa por sí misma pérdidas asociadas al contrato $^{77}$. Siguiendo la regla tradicional, se pretende devolver al perjudicado a la situación anterior a la conclusión del contrato.

\section{- Convergencia de los remedios contractuales y precontractuales}

Como se indicó, el incumplimiento de los deberes de información puede traer aparejos remedios contractuales y precontractuales. Se discute si en estos supuestos la parte afectada puede optar por cualquiera de ellos o si, por el contrario, existen remedios preferentes. En este punto no existe una solución unánime. Los PECL, por ejemplo, se decantan por la concurrencia de remedios, dejando en manos del actor la elección. En este proyecto se reconoce que en ocasiones la anulación podría ser más útil en comparación con los remedios contractuales ${ }^{78}$.

Los Principios Unidroit, por el contrario, prefieren los remedios contractuales -cuando procedan- según lo dispuesto en el artículo 3.2.4. Esta solución viene dada por la flexibilidad del sistema remedial asociado al incumplimiento del contrato que permite una mejor respuesta que la nulidad del contrato ${ }^{79}$. Como se vio, esta solución también ha sido compartida por un sector de la doctrina ${ }^{80}$ teniendo en cuenta que el incumplimiento de los deberes de información se proyecta en el objeto y contenido del contrato; esta línea también ha sido seguida por las propuestas de directiva de consumo descritas en el acápite anterior. 


\section{Conclusión}

La naturaleza de la responsabilidad precontractual es una cuestión controversial que sigue suscitando debate. Esta discusión, no obstante, sigue dando prevalencia a la naturaleza del vínculo relacional que surge en la negociación y pierde de vista la complejidad del proceso negociador y su necesaria interacción con el contrato. Por ello se pone de presente la necesidad de abordarlos de forma conjunta.

Así las cosas, la responsabilidad contractual debería entenderse como el régimen encargado de resolver las controversias surgidas en el marco de una relación regida por el derecho de contratos. Con todo, debe señalarse que el incumplimiento precontractual no es asimilable al incumplimiento contractual, por ello precisa de un sistema remedial singular que se integre a la teoría general del contrato.

De esta manera se podría dotar de mayor coherencia al sistema y podría, por ejemplo, establecerse mejores criterios de solución para aquellos incumplimientos precontractuales que pueden proyectarse sobre el contrato mismo. El incumplimiento del deber de información es, sin duda, el supuesto que ilustra en mejor medida la cuestión porque los efectos de su incumplimiento se proyectan por igual en la negociación y en el contrato. Frente a esta disyuntiva, en ocasiones se ha optado por la alternancia de los remedios precontractuales y los contractuales; en otras, se han preferido los remedios contractuales.

\section{Referencias}

Albiez Dohrmann, Klaus. "Un nuevo Derecho de obligaciones. La Reforma 2002 del BGB". Anuario de Derecho Civil 55, n. ${ }^{\circ} 3$ (2002): $1133-$ 1228. https://www.boe.es/publicaciones/anuarios_derecho/abrir_pdf. php?id=ANU-C-2002-30113301228.

Alonso Pérez, Mariano. "La responsabilidad precontractual". Revista Crítica de Derecho Inmobiliario 485 (1971): 859-922.

Arrubla Paucar, Jaime. Contratos mercantiles: Teoría General del Negocio Mercantil. 13. a ed. Bogotá: Legis, 2012.

Asúa González, Clara I. La culpa in contrahendo: tratamiento en el derecho alemán y presencia en otros ordenamientos. Bilbao: Servicio Editorial, Universidad del País Vasco, 1989. 
Bar, Christian von, y Eric Clive. Principles, definitions and model rules of European private law: Draft Common Frame of Reference (DCFR) Full Edition. Munich: Sellier, 2009.

Bernal Fandiño, Mariana. "La naturaleza jurídica de la responsabilidad civil derivada de la inobservancia de los deberes colaterales de conducta". Vniversitas 62, n. ${ }^{\circ} 126$ (2013): 39-64. https://revistas.javeriana.edu.co/ index.php/vnijuri/article/view/6120.

Betti, Emilio. Teoria General del Negocio Jurídico. Granada: Comares, 2000.

Bianca, Massimo. Derecho Civil: El contrato. 2. a ed. Bogotá: Universidad Externado de Colombia, 2007.

Borda, Alejandro. "La buena fe en la etapa precontractual". Vniversitas 63, n. ${ }^{\circ} 129$ (2014): 39-79. https://doi.org/10.11144/Javeriana.VJ129.Ibfe.

Brebbia, Roberto. Responsabilidad precontractual. Buenos Aires: Editorial La Roca, 1987.

Brooks, R.W. "The Efficient Performance Hypothesis". The Yale Law Journal 116, n. ${ }^{\circ} 3$ (2006): 568-96. https://digitalcommons.law.yale.edu/ylj/ vol116/iss3/2.

Cabanillas Sánchez, Antonio. "El ámbito de la responsabilidad precontractual o culpa in contrahendo". Revista Crítica de Derecho Inmobiliario 628 (1995): 747-88. https://dialnet.unirioja.es/servlet/articulo?co digo $=34295$.

Caramelo, Gustavo. "Sección 3a. Tratativas contractuales". En Código Civil y Comercial de la Nación Comentado [t. III]. Editado por Marisa Herrera, Gustavo Caramelo y Sebastián Picasso, 392-97. Buenos Aires: Infojus, 2015.

Carreño Mendoza, Sergio. "La ruptura de la negociación: la potestad de retiro y los motivos que acompañan su ejercicio en el derecho privado". Revista de Derecho Privado, n. ${ }^{\circ} 36$ (2019): 233-55. https://doi. org/10.18601/01234366.n36.08.

Cupis, Adriano de. El Daño: teoría general de la responsabilidad civil. Barcelona: Bosch, 1975.

Farnsworth, E. Allan. "Your Loss or My Gain? The Dilemma of the Disgorgement Principle in Breach of Contract". Yale Law Journal 94, n. ${ }^{\circ} 6$ (1985). https://digitalcommons.law.yale.edu/ylj/vol94/iss6/4.

Fauvarque-Cosson, Bénédicte, y Denis. Mazeaud. European Contract Law: Material for a Common Frame of Reference. Munich: European Law Publishers, 2008. 
Fried, Charles. Contract as promise: a theory of contractual obligation. Cambridge, Mass.: Harvard University Press, 1981.

García Rubio, María Paz. La responsabilidad precontractual en el derecho español. Madrid: Tecnos, 1991.

García Rubio, María Paz. "La responsabilidad precontractual en la propuesta de modificación del derecho de obligaciones y contratos". Anuario de Derecho Civil LXIII (2010): 1622-42. https://www.boe.es/publicacio nes/anuarios_derecho/abrir_pdf.php?id=ANU-C-2010-40162101642.

García Rubio, María Paz. "Perspectiva y prospectiva en tres casos de responsabilidad surgida en la etapa de negociación de un contrato". En Nuevas perspectivas del derecho contractual. Editado por Esteve Bosch Capdevila, 261-90. Barcelona: Bosch, 2012.

Gómez Pomar, Fernando. "El incumplimiento contractual en Derecho español”. InDret 3 (2007): 1-48. https://www.raco.cat/index.php/InDret/ article/view/78949/103090.

Gómez Pomar, Fernando. Previsión de daños, incumplimiento e indemnización. Madrid: Civitas, 2002.

Hilsrerand, Arthur. Las obligaciones precontractuales. Pamplona: Analecta Editorial, 2005.

Katz, Avery. "When should an offer stick? The Economics of Promissory Estoppel in Preliminary Negotiations". The Yale Law Journal, 105 (1996): 1250-1309. https://digitalcommons.law.yale.edu/cgi/viewcontent.cgi? article $=7672 \&$ context $=y$ lj.

Lando, Ole y Hugh Beale. Principles of European contract law. Parts I and II, combined and revised. Editado por Ole Lando y H. G. Beale. The Hague: Kluwer Law International, 2000.

Markesinis, Basil; Hannes Unberath y Angus Johnston. The German Law

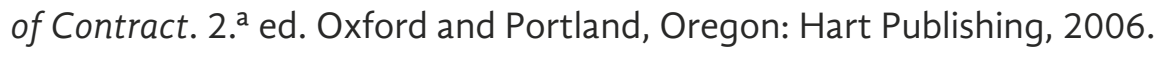

Mazeaud, Henri, y Léon Mazeaud. Traité théorique et pratique de la responsabilité civile [t. I]. Paris: Librairie du Recueil Sirey, 1947.

Medicus, Dieter. Tratado de las relaciones obligaciones. Barcelona: Bosch, 1995.

Monsalve Caballero, Vladimir. Responsabilidad precontractual: la ruptura injustificada de las negociaciones. Bogotá: Ibáñez, 2010.

Morales Moreno, Antonio Manuel. “¿Es posible construir un sistema precontractual de remedios? Reflexiones sobre la propuesta de modenización del derecho de obligaciones y contratos en el marco del derecho 
europeo". En Derecho privado europeo y moderninización del derecho contractual en España. Editado por Klaus Albiez Dohrmann, 400-422. Barcelona: Atelier, 2011.

Morales Moreno, Antonio Manuel. Incumplimiento del contrato y lucro cesante. Cizur Menor (Navarra): Civitas Thomson Reuters, 2010.

Mosset Iturraspe, Jorge. Responsabilidad precontractual. Santa Fe: Rubinzal-Culzoni Editores, 2006.

Neme Villarreal, Martha. "La buena fe es un principio que se expresa mediante cláusulas generales cuya reiterada aplicación tiene por virtud generar estándares de conducta". En Jornadas Franco-Colombianas "Los grandes estándares del derecho francés", 1-34, 2012.

Oviedo Albán, Jorge. "Tratos preliminares y responsabilidad recontractual”. Vniversitas, 115 (2008): 83-116. https://revistas.javeriana.edu.co/ index.php/vnijuri/article/view/14577/11759.

Pantaleón, Fernando. "Comentario al artículo 1902 CC". En Comentarios del Código Civil, 1993-95. Madrid: Ministerio de Justicia, 1993.

Pascual Estevill, Lluis. Derecho de daños: principios generales, responsabilidad contractual, extracontractual y responsabilidad precontractual. Barcelona: Bosch, 1995.

Planiol, Marcel y Georges Ripert. Traité Pratique de Droit Civil Français [t. VI]. Paris: Librairie Générale de Droit y de Jurisprudence, 1930.

Puig Brutau, José. Fundamentos de derecho civil [t. II, vol. I] Doctrina General del Contrato. Barcelona: Bosch, 1989.

Rengifo Gardeazábal, Mauricio. La formación del contrato. Bogotá: Universidad de los Andes - Editorial Temis, 2016.

Rodríguez de las Heras Ballell, Teresa. "La etapa precontractual en la contratación mercantil". En Estudios sobre el futuro código mercantil: libro homenaje al profesor Rafael Illescas Ortiz. Editado por María José Morillas Jarillo, María del Pilar Perales Viscasillas y Leopoldo José Porfirio Carpio, 1801-20. Getafe: Univerdidad Carlos III, 2015.

Salgado Ramírez, Catalina. "Breve introducción a la responsabilidad precontractual en la teoría de Rudolf von Jhering". En Estudios de Derecho Civil en memoria de Fernando Hinestrosa, tomo I, 721-58. Bogotá: Universidad Externado de Colombia, 2014.

Salgado Ramírez, Catalina. "Consideraciones históricas acerca de la responsabilidad precontractual antes de Rudolf von Jhering. Aproximación doctrinal". Revista de Derecho Privado, 22 (2012): 277-98. https://revis tas.uexternado.edu.co/index.php/derpri/article/view/3196. 
Santos Ballesteros, Jorge. Instituciones de Responsabilidad Civil [t. II]. 2. ${ }^{a}$ ed. Bogotá: Pontificia Universidad Javeriana, 2008.

Scognamiglio, Renato. Teoría General del Contrato. Bogotá: Universidad Externado de Colombia, 1996.

Scott, Robert E. y George G. Triantis. "Anticipating litigation in contract design". Yale Law Journal 115, n. ${ }^{\circ} 4$ (2006): 814-79. https://www.yale lawjournal.org/pdf/339_a5pzok3k.pdf.

Stiglitz, Rubén. Responsabilidad precontractual: incumplimiento del deber de información. Buenos Aires: Abeledo-Perrot, 1992.

Unidroit. “Unidroit principles 2016”. Roma, 2016.

Zimmermann, Reinhard, y Simon Whittaker. «Good Faith in European Contract Law: Surveying the legal Landscape». En Good faith in European Contract law, editado por Reinhard Zimmermann y Simon Whittaker, 7-62. Cambridge: Cambridge University Press, 2000.

\section{Jurisprudencia}

Corte Suprema de Justicia. Sala de Casación Civil, sentencia 4962, 31 de mayo de 1998, MP: Rafael Romero Sierra.

Corte Suprema de Justicia, Sala de Casación Civil, sentencia C-5295, 23 de junio de 2000, MP: José Fernando Ramírez Gómez.

Corte Suprema holandesa, sentencia Plas vs. Valburg, NJ 1983/723.

Corte Suprema holandesa, sentencia Felix vs. Aruba, NJ 1993/287.

Tribunal de Justicia Europeo, sentencia C-334/00 Fonderie Officine Meccaniche Tacconi c/Heinrich Wagner Sinto Maschinenfabrik, 17 de septiembre de 2002.

Tribunal Supremo español, Sala de lo Civil, sentencia RJ 1997/3668, 3 de mayo de 1997.

Tribunal Supremo español, Sala de lo Civil, sentencia Tol 2364, 14 de junio de 1999.

Tribunal Supremo español, Sala de lo Civil, sentencia Tol 2610, 11 de abril de 2000.

Tribunal Supremo español, Sala de lo Civil, sentencia RJ 2007/6811, 9 de octubre de 2007.

Tribunal Supremo español, Sala de lo Civil, sentencia RJ 2011/7400, 15 de octubre de 2011. 